\title{
SIDE-SCAN SONAR TECHNIQUES FOR THE CHARACTERIZATION OF PHYSICAL PROPERTIES OF ARTIFICIAL BENTHIC HABITATS*
}

\author{
Wen-Miin Tian** \\ National Sun Yet-sen University \\ Department of Marine Environment and Engineering \\ (70, Lien-Hai Road, Ku-Shan District, Kaohsiung City, Taiwan 804 ROC, Taiwan) \\ **Corresponding author: tiwemi@ mail.nsysu.edu.tw
}

\begin{abstract}
A B S T R A C T
Side-scan sonar observations conducted at Mito artificial habitat site in the southwest coast off Taiwan, documented the locations of both concrete cubic blocks (more than 10,000 units) and scrapped steel boats (39 units) deployed previously. Based on their geographic locations, the concrete cubic artificial reefs could be grouped into 14 reef sets. About $30 \%$ of the reefs were deployed out of the promulgated site area. For the purpose of artificial habitat site identification and fishery resources management, a database structure was designed to accommodate types and positions of reefs, information of reef sets, bathymetric contours, textures of bottom sediments and geomorphological characteristics. The effectiveness of Mito artificial habitat site was evaluated to be positive after the deployment of both concrete block reefs and steel boat reefs.
\end{abstract}

\section{RESUMO}

Observações com sonar de varredura lateral ao largo de Mito na costa sudoeste de Taiwan, revelou a localização de mais de 10.000 blocos de concreto e 39 embarcações de ferro assentados previamente como recifes artificiais. Com base nas imagens obtidas, os cubos de concreto formam 14 grupos separados. Cerca de 30\% das unidades de concreto foram assentadas fora das áreas previstas. Para a identificacão correta dos recifes artificiais e manejo adequado dos recursos pesqueiros, foi organizada uma base de dados com informações sobre forma, materiais e posição, e arranjo espacial das unidades recifais, bem como dados de batimetria, natureza do sedimento do fundo e geomorfologia. A eficiência dos recifes artificiais de Mito foi avaliada positivamente após o assentamento tanto das unidades de concreto quanto das embarcações de ferro.

Descriptors: Artificial habitat, Side-scan sonar, Survey route design, Positioning of artificial reefs, Surficial sediments, Fishery resources.

Descritores: Habitat artificial, Sonar de varredura lateral, Desenho rota amostral, Posicionamento de recifes artificiais, Sedimentos superficiais, Recursos pesqueiros.

\section{INTRODUCTION}

Artificial benthic habitats have long been deployed for promoting coastal and nearshore fishery resources. The major functions of artificial benthic habitats include: (i) the aggregation of organisms to enable more efficient fishing, (ii) the increase of natural productivity by providing new habitats for encrusting organisms which contribute to food chains, (iii) the creation of habitats for desired target species, and (iv) the protection of small/juvenile organisms and nursery areas from destructive fishing gear (CHOU, 1997; SEAMAN JR; SPRAGUE, 1991). There are literally hundreds of artificial habitat designs deployed around the world and the materials used are fairly limited in number (i.e., concrete and steel) (VIK, 1982). In fact, it is evident that almost any submerged

(*) Paper presented at the $9^{\text {th }}$ CARAH - International Conference on Artificial Reefs and Related Aquatic Habitats on 8-13 November, Curitiba, PR, Brazil. object in an appropriate location is capable of increasing or concentrating fish populations. Aside from monitoring the fish-attraction effectiveness of a particular artificial habitat, it is necessary to conduct follow-up investigations thereby determining whether or not (i) the habitat is and remains within the promulgated area after installation and (ii) the structure of the habitat is still intact after the passage of a certain period of time. The objectives and applications of these positioning investigations of the artificial habitats are crucial to a broad variety of issues such as jurisdiction, safety of navigation, fishing and diving activities, ecological and engineering evaluations, as well as fishery resources management.

There are a variety of available techniques, such as scuba diving, underwater television and acoustic equipment such as the single-beam echo sounder or acoustic fish finder, the multi-beam echo sounder and side-scan sonar (KENNY, et. al., 2003; 
ANDERSON, et. al., 2008), which may be used in the search for locations for and the positioning and monitoring of artificial benthic habitats. Among them, the first three, i.e., scuba diving, underwater television and the fish finder, are the most frequently used for the evaluation of the effectiveness of artificial habitats. Optical images are collected by both scuba diving and underwater television surveying. However, effective light transmission under water is, even in the best of circumstances, usually limited to a few meters. Scuba diving is extremely effective for investigation into the physical properties of reefs and fish-attraction conditions, but it is rather limited by diving depth and duration, and also by visibility. It is also difficult to grasp the entire situation of a habitat site covering a large area at a great depth of water. Although deeper areas can be investigated, underwater television or a remotely operated vehicle (ROV) is much more hindered by poor visibility than are divers and the visible angle is rather narrow. On the other hand, the echo sounder or fish finder, which utilizes ultrasonic waves to determine underwater objects such as fish (FURUNO, 1996), has difficulty in describing the form of a habitat in detail. In addition, due to the narrow, low-resolution footprint and sampled volume across-track of this type of instrument, only the habitats of sufficient height and directly beneath its transducer can be properly identified. This instrument is, nevertheless, useful for grasping the overall concentration or distribution area of closely spaced habitats.

In Taiwan, a comprehensive project for the construction and deployment of artificial reefs to enhance commercial fisheries was initiated in 1973. Since then, the government has invested about $\$ 80$ million in this long-term program and over 220,000 units of various types of artificial habitats have been deployed at 88 sites (FISHERY ADMINISTRATION, TAIWAN, 2009). As far as follow-up investigations are concerned, the fish finder and scuba diving have been the most frequently utilized techniques in conducting the search for and for the locating, positioning and monitoring of the habitats. A normal procedure for this work includes employing an echo sounder (or fish finder) following either a zig-zag or outflanking course in the initial phase of the search for the habitat. After the habitats had been detected and recognized, a random repetition navigation course was used to identify their extent. Scuba diving observations were then conducted for investigation into the piling up or scattering and the scouring and burying of reefs, sessile organisms and fish-attraction conditions. Due to factors such as: poorly documented information as to the actual locations of the habitats, the influence of heavy seas, difficulties in navigation, accuracy of navigation equipment, and poor visibility during scuba diving observations, only a limited proportion of the deployed habitats were detected, identified and investigated (e.g., OH ET AL., 1993). There are several possible reasons for those artificial habitats not having been detected by this working procedure. Some of them might have been partially or completely buried by the hydrodynamic activities of the environment. However, it may be supposed that a lot of them might still be sitting on the seafloor intact, just waiting for the proper equipment and procedures for their detection and identification.

To meet the needs as regards the search for and the recognition and positioning of the artificial habitats deployed off Taiwan, an intrinsic methodology was adapted, evaluated and standardized. This technique, which incorporated the knowledge and practices of underwater acoustical surveying and image processing, consists of a side-scan sonar system, a positioning satellite system (GPS), a subsurface navigation system, and a sonar image acquisition and processing system. The main objectives of the present study were thus: (i) to quantify the feasibility of using side-scan sonar in identifying deployed artificial habitats, (ii) to establish an effective and reliable procedure to conduct the search for, and the detection, recognition and location of artificial benthic habitats, and (iii) to document physical and environmental information on the artificial habitat site and integrate the results into a database framework for site identification and management. The specific site selected for this investigation was the Mito artificial habitat located off the southwestern coast of Taiwan (Fig. 1).

\section{Side-SCAn Sonar Techniques}

Side-scan sonar is an active sonar system which implements the characteristics of sideways look, two channels, narrow beam, and towed body. Unlike the depth sounder or fish finder, the side-scan sonar system has been defined as an acoustic imaging device used to provide wide-area and large-scale pictures of the floor of a body of water to locate features and objects on the seabed (FISH; CARR, 1990). The great potential of the side-scan sonar system had been proven in the various disciplines of marine science. More particularly, the application of the system is wide-ranging in marine geology, marine biology, hydrography, underwater archaeology, oceanic engineering, and surveys for military purposes. Regarding the monitoring technologies of benthic artificial habitats, the side-scan sonar system has been proposed as the most practical (KENNY, et. al., 2003; COLLIER; BROWN, 2005). However, due to the cost of the system, the complexities of its operation procedures, the necessities of a precise track chart for the ship, and extensive period of time and 
experience for data processing and analyzing, only limited applications of this system in monitoring and delineating the boundaries of benthic artificial habitats have been reported (BELL; HALL, 1994; MUNOZPEREZ at al., 2000; GROVE et al., 2002; TURPIN; BORTONE, 2002; COLLIER; BROWN, 2005).

The major equipment employed in this investigation is listed as follows:

(1) Side-scan sonar system (Klein Hydroscan 590 Sonar):

(a) Klein 595 digital graphic sonar recorder.

(b) Klein $422 \mathrm{~S}-101 \mathrm{HF}$ dual frequency $(100 / 500$ $\mathrm{kHz}$ ) towfish.

(c) Sea Mac winch and Kevlar cable.

(2) Satellite positioning and navigation system:

(a) Differential global positioning system, DGPS, (KGP-931D, Koden Electronics Co.)

(b) Integrated navigation and charting system (SeaPlot Professional, V 5, Advanced Marine Technology Corp.)

(3) Subsurface navigation system (LXT Underwater Tracing System, ORE International, Inc.)

(a) Command/display unit (Model 4430B)

(b) Hydrophone (Model 4213B)

(c) Telemetry multibeacon (Model 4337B)

(d) Heading sensor (Model 4411B)

(e) Integrated positioning system (software version 3.26)

(4) Data acquisition, storage, and processing system:

(a) Sonar acquisition and processing system $\left(\mathrm{EOSCAN}^{\mathrm{TM}}\right.$, Polaris Imaging, Inc.)

(b) Side-scan sonar mosaicking software (EOMAP ${ }^{\mathrm{TM}}$, Polaris Imaging, Inc.)

(c) Sonar image viewing software (self developed)

(d) Slant range correcting software (self developed)

An important issue regarding side-scan sonar surveying is the assignment of absolute geographical coordinates to targets (such as artificial habitats) identified in the sonar imagery. This issue involves the sonar towfish ground speed, its position relative to the towing platform and the seabed, its roll, pitch and yaw, and the absolute coordinates of the towing platform. In this investigation, the differential globe positioning system (DGPS, with precision of $\pm 5 \mathrm{~m}$ at a probability of 95\%) was employed to position the towing platform; while the position of the towfish relative to the towing platform was determined by a subsurface navigation system. The absolute geographical coordinates of the towfish were then provided by incorporating both data through an integrated positioning system.

Both sonar imagery and towfish coordinates were integrated by a data acquisition system to form geocoded sonar imagery. This geocoding process allows sonar imagery to be registered precisely on a chosen map projection and absolute geographical locations to be assigned to targets identified in the imagery. For the purpose of data management and visualization, a whole area sonar image map was created by combining swaths of geocoded imagery through a process of mosaicking.

The detection and recognition of a specific object on the seafloor, such as a meter-sized concrete cubic artificial reef, with a side-scan sonar system involve four interdependent components, i.e., object, surveying hardware, field operation and environmental factors. An effective and optimized side-scan sonar survey should, therefore, incorporate the mutual considerations of the following three aspects, i.e., the detectability of the object, the resolution of the sonar image and the quality of the sonar image. The fundamental criterion for the detectability of a specific object is that if the object can provide sufficient backscattered acoustic energy to the receiving transducers and if the ambient background backscatter is both uniform and low, then the object can be detected as a sonar target. Theoretically, the backscattering is affected, in decreasing importance, by the geometry of the sensor-target system (relative angle of ensonification), the morphological characteristics of the surface (e.g., micro-scale roughness) and by its intrinsic nature (composition, density, impedance, relative importance of volume and surface reverberation) (BLONDEL; MURTON, 1997; BLONDEL, 2000; LURTON, 2002; TIAN, 2008). Acoustic impedance (the product of density, $r$ and compressional wave velocity, $c$ ) can be used to define the reflection coefficient, $R$ for normal incidence, which is a measure of the strength of the reflection (KINSLER, et. al., 1982).

The reflection coefficient for sound traveling from sea water into a concrete artificial habitat is about $46 \%$ (MAZEL, 1985). However, it is only about $11 \%$ for surficial sediments composed of sand (by using $\mathrm{r}=1800 \mathrm{~kg} / \mathrm{m}^{3}, \mathrm{c}=1700 \mathrm{~m} / \mathrm{s}, \mathrm{CHEN}$; CHERN, 1997). The difference of reflection coefficient between concrete artificial habitat and surficial sediments corresponds to different shades of gray on the sonographs. In addition, an object protruding above the bottom will prevent sound from reaching the sea floor for some distance beyond the object. This will produce an acoustic shadow zone which appears on the record as a white area. Therefore, based on the phenomena of darker shades, acoustic shadow zone, their dimensions and the highly regularly shaped external configurations with straight edges, the artificial reefs can be identified visually on the sonographs collected by a side-scan sonar (MAZEL, 1985; QUINN et. al., 2005).

The resolution of the sonar image, which has been labeled as image processing resolution (TYCE, 1986) or pixel size, can be obtained by simply 
dividing the distance of the full swath width by the total number of pixels displayed. Operational factors which control the resolution of the sonar image include: frequency, horizontal aperture, pulse length, range scale and tow speed. The ranges used in sidescan sonar surveys are very important and should be selected with forethought during the operational planning stage. There is a trade-off between spatial resolution and swath width which can be correlated either to produce detailed images for feature identification or to map large areas. Long sonar ranges utilize fewer outgoing pulses per second (i.e., low pulse repetition rate) than shorter range settings. This limits system detectability of objects on the seafloor as well as operator recognition of such targets. Further, the longer range settings scan a larger area of the seafloor and, since the display is of a fixed size, compress the resultant images.

The quality of the sonar image plays an important role regarding proper detection and recognition of objects on the seafloor. It can be degraded by two types of factors; i.e., distortion due to an unstable towfish and interference due to acoustical or electrical noise. Ideally, the side-scan sonar towfish should be moving perfectly straight at constant speed. In practice this can never be achieved. If the towfish is pitching or yawing due to turbulence or heave action on the towcable, the sonograph images can become quite distorted or even blurred. Interference due to acoustic noise includes depth sounders, sparkers, propellers, and ship's machinery. The cause of electrical noise may be power supply problems, cable faults, component failures, or other sources (e.g., radio banding). In order to acquire a good quality sonar image, necessary preventive activities should be taken to reduce or eliminate this distortion and interference.

A comprehensive description regarding basic principles, sonar design details, and underwater acoustics of the side-scan sonar system are beyond the scope of the present discussion and can be located in the literature (ex. JOHNSON; HELFERTY, 1990; KINSLER, et. al. 1982; LURTON, 2002; URICK, 1975).

\section{Site Specification and Field Surveyings}

Officially promulgated in 1986, the Mito artificial habitat site, centered at $22^{\circ} 46.79 \mathrm{~N}$, $120^{\circ} 9.58 \mathrm{E}$ (WGS-84 map datum) with a radius of $1,000 \mathrm{~m}$ and in water depth of about $22 \mathrm{~m}$, covers a circular area of $3.2 \mathrm{~km}^{2}$ off the southwestern coast of Taiwan. The types of artificial habitats deployed at this permitted site include small $(1 \times 1 \times 1 \mathrm{~m})$ and large $(2 \times 2 \times 2 \mathrm{~m})$ specifically manufactured concrete cubic blocks and scrapped steel fishing boats (about 40 x $7 \times 6 \mathrm{~m}$ ). For a period of about 10 years after its promulgation, 9,095 units of large block, 2,075 units of small block, and 43 scrapped fishing boats were deployed at this site. Navigation and positioning instruments, such as radar, visual observation of nearby landmarks, as well as the globe positioning system (GPS) were employed during the deployment of these reefs. However, due to a lack of a systematic documentation procedure, the actual positions of these reefs were not precisely recorded and documented. Failures to locate these reefs in the post deployment and follow-up observations by the application of echo sounders and scuba divers have commonly been reported (e.g.,. OH et al., 1993; LIN, 1999).

For the purpose of effectively locating and documenting the reefs at the Mito artificial habitat site, three phases of field side-scan sonar surveying operations were proposed and conducted, i.e., calibration surveying, preliminary site surveying and detailed site surveying. The purpose of the calibration surveying is to obtain the optimal side-scan sonar settings over which an operator may exercise control (i.e., frequency, range scale, towing speed, and towing altitude, etc.) and which are required in the search for and identification of the specific objects for the subsequent surveying operations (i.e., preliminary and detailed site surveying). The preliminary site surveying is to define and delineate the boundaries or the most potential areas where the artificial reefs are located within an economically short period of time. In this phase, the working criterion is to collect high area coverage rate images with feature resolution feasible for the detection of the existence of the objects. The detailed site surveying is to detect, identify and locate the reefs, tag their locations with GPS coordinates individually, and evaluate their physical status in the defined potential area. Therefore, the priority at this phase is to produce detailed images with proper feature resolution for the recognition and evaluation of the objects. In addition to geocoded sonar imagery, information such as water depth and surficial sediment samples were collected by an echo sounder system (Simrad EK-500) and a grab sampler (Shipak sampler), respectively. Bathymetric map and sediment grain size distribution properties were obtained thereafter. The field surveying was performed aboard the research vessel "Ocean Research\#3" and was conducted during the period from 2003 to 2005.

\section{Calibration Surveying}

To fulfill the necessity of searching for, locating, recognizing, positioning and evaluating the habitats, a series of side-scan sonar operation settings (i.e., frequency, range scale, towing speed, and towing altitude) were tested and evaluated on well documented objects (i.e., 100 units of $2 \times 2 \times 2 \mathrm{~m}$ concrete cubic blocks) at a specific site near the Mito artificial habitat site (i.e., Yun-An artificial habitat 
site, Fig. 1) (TIAN; LIN, 2003). From a practical point of view, to fulfill the task of object detection by the application of a side-scan sonar system, the minimum requirement is that the object must receive five sonar insonifications (pings). On the other hand, for the purpose of recognizing, positioning and evaluating a specific object, a conservative plan should include one which chooses tow speeds and ranges that will allow for at least 12 insonifications in a forward travel distance equal to the object's least dimension (FISH; CARR, 1990). The parameters affecting the number of insonifications an object receives are: sonar range scale (which sets pulse repetition rate), tow speed and horizontal beam directivity (i.e., horizontal aperture). Among these three parameters over which the operator exercises control are range scale and tow speed.

The specific side-scan sonar settings tested include $100 \mathrm{kHz}$ with ranges of 150 and $100 \mathrm{~m}$ (per channel) as well as $500 \mathrm{kHz}$ with ranges of 75 and 50 $\mathrm{m}$ (Table 1). The results of the side-scan test runs are summarized in the four sonographs in Figure 2. The calibration tests demonstrated that the targets could be successfully detected and imaged by the side-scan sonar with varying degrees of resolution and detectability. The identification phenomena of artificial habitats at this specific site include darker image shades (or highlights), highly regularly shaped external configurations with straight edges, physical dimensions, distribution pattern, and acoustic shadow zones.

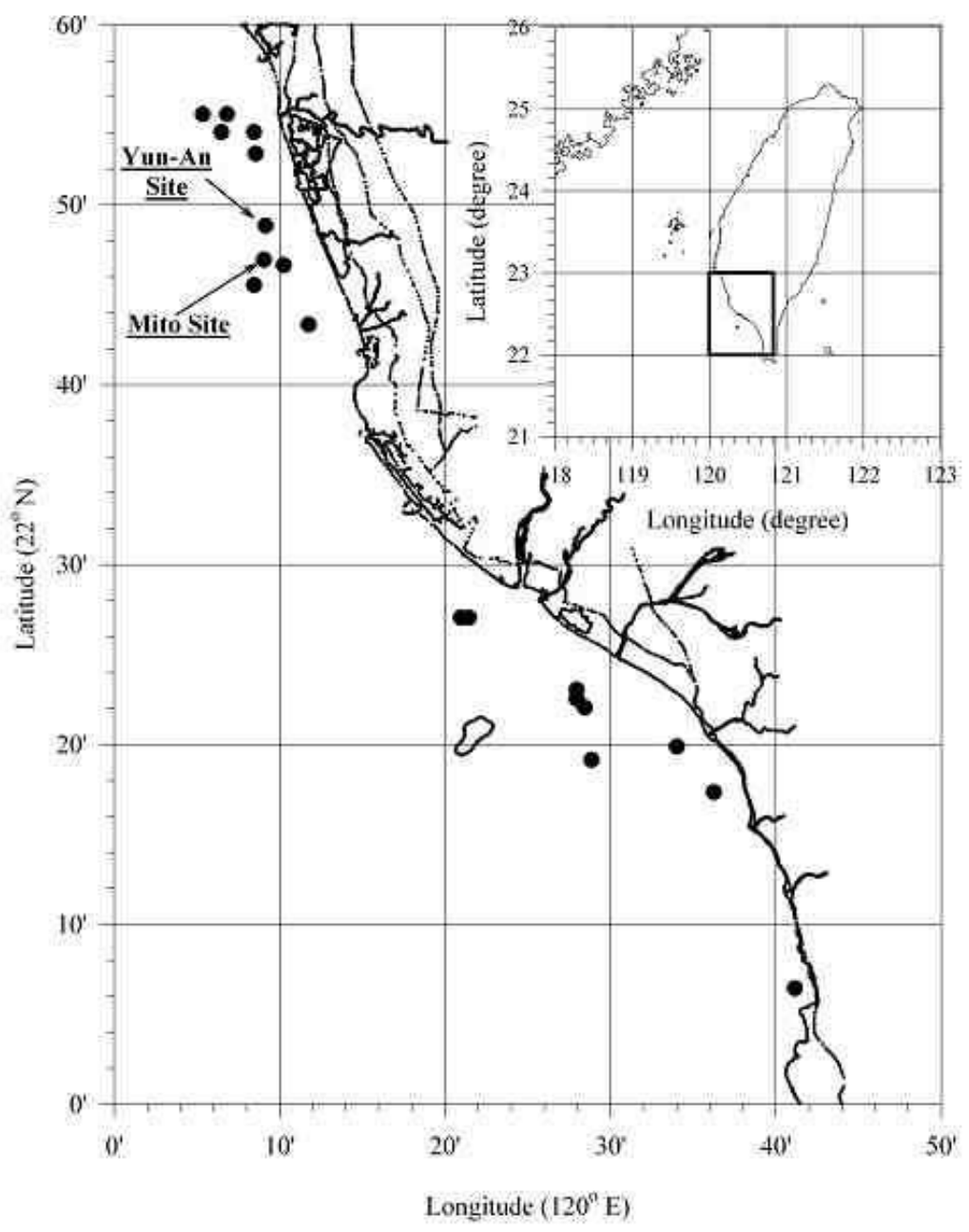

Fig. 1. Locations of Mito and Yun-An artificial habitat site. Nineteen artificial habitat sites were constructed off the southwestern coast of Taiwan. 
Table 1. Results of side-scan sonar calibration survey

\begin{tabular}{|c|c|c|c|c|}
\hline Test\# & 1 & 2 & 3 & 4 \\
\hline $\begin{array}{l}\text { frequency } \\
(\mathbf{k H z})\end{array}$ & 100 & 100 & 500 & 500 \\
\hline $\begin{array}{l}\text { range scale } \\
\text { (m) }\end{array}$ & 150 & 100 & 75 & 50 \\
\hline $\begin{array}{l}\text { pixel resolution* } \\
(\mathrm{cm})\end{array}$ & 14.6 & 9.7 & 7.3 & 4.9 \\
\hline $\begin{array}{l}\text { horizontal aperture } \\
\text { (degree) }\end{array}$ & 1.0 & 1.0 & 0.2 & 0.2 \\
\hline $\begin{array}{l}\text { pulse length } \\
\text { (ms) }\end{array}$ & 0.10 & 0.10 & 0.02 & 0.02 \\
\hline $\begin{array}{l}\text { pulse repetition rate } \\
\text { (pulse/sec) }\end{array}$ & 5 & 7.5 & 10 & 15 \\
\hline $\begin{array}{l}\text { no. of pulse/m } \\
\text { (@ } 3 \text { kts) }\end{array}$ & 3.3 & 5.0 & 6.6 & 10 \\
\hline block resolution & barely identified & $\begin{array}{l}\text { good in identify groups but } \\
\text { not individually }\end{array}$ & $\begin{array}{l}\text { identify block } \\
\text { individually }\end{array}$ & $\begin{array}{l}\text { identify block } \\
\text { individually and } \\
\text { precisely }\end{array}$ \\
\hline surveying suggestions & --- & $\begin{array}{l}\text { settings for preliminary } \\
\text { surveying }\end{array}$ & $\begin{array}{l}\text { settings for } \\
\text { detailed surveying }\end{array}$ & $\begin{array}{l}\text { settings for } \\
\text { more detailed surveying }\end{array}$ \\
\hline
\end{tabular}

* Pixel Resolution $=$ Range/1024.

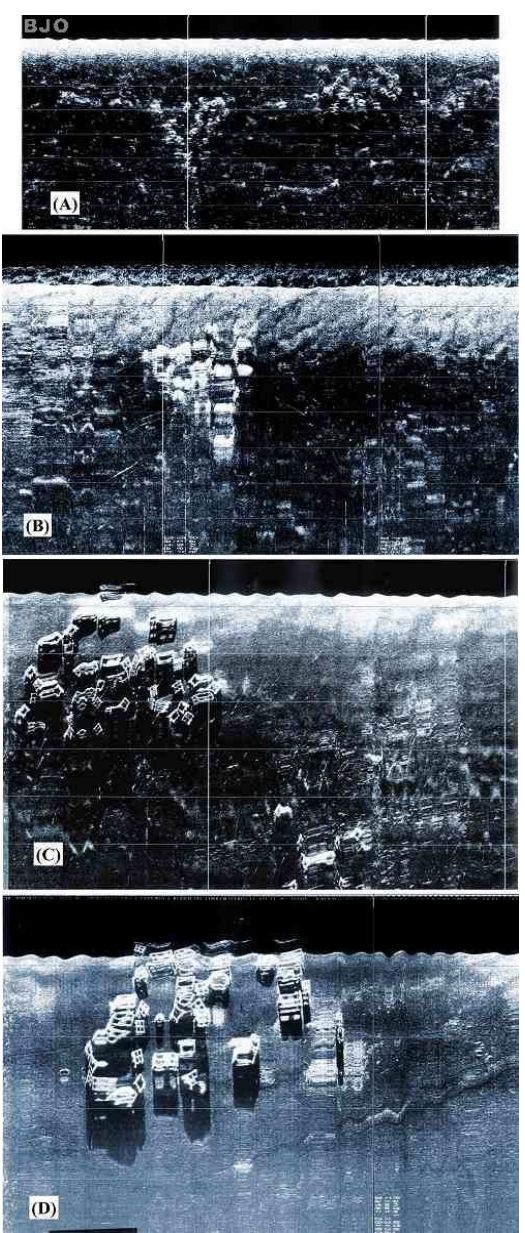

Fig. 2. Side-scan sonar imagery showing detectability and resolution conditions of concrete blocks at Yun-An site. (A) $100 \mathrm{kHz}$ with range setting at $150 \mathrm{~m}$, (B) $100 \mathrm{kHz}$ with range setting at $100 \mathrm{~m},(\mathrm{C}) 500 \mathrm{kHz}$ with range setting at $75 \mathrm{~m}$, (D) $500 \mathrm{kHz}$ with range setting at $50 \mathrm{~m}$. 
Based on the visual observations of the images collected, it was concluded that: (i) $100 \mathrm{kHz}$ images with slant range setting at $100 \mathrm{~m}$, towing speed of 3 knots, and towing altitude of $10 \mathrm{~m}$ above bottom were adequate for preliminary site surveying. (ii) 500 $\mathrm{kHz}$ images with slant range setting at $75 \mathrm{~m}$, towing speed of 3 knots, and towing altitude of $10 \mathrm{~m}$ were sufficient for detailed site surveying. $500 \mathrm{kHz}$ with shorter range settings, such as 50 or even $30 \mathrm{~m}$, provide a far greater recognizability of the reefs. These shorter range settings can sometimes be used even for the detection of the existence of organisms encrusted on the reefs. However, this will give smaller area coverage, thus increasing ship time during a general area survey. It is worth noting that in the process of evaluating the sonographs through visual observation, the inverted (or light) images in which low backscatter is dark and high backscatter is bright can help in identifying the existence of artificial reefs.

\section{Preliminary Site Surveying}

During the preliminary site surveying, or searching phase, the most potentially promising areas as regards the location of the artificial reefs will be defined. Since no information on the real or even the approximate locations of the reefs was available, an area of over 5 times that of the permitted site area (i.e., $16 \mathrm{~km}^{2}$ ) was searched with meshed track lines and line spacing of about $400 \mathrm{~m}$. The specific side-scan sonar settings used are $100 \mathrm{kHz}$ with range of $100 \mathrm{~m}$. During this surveying, an onboard computer graphically displays the planned track of the vessel. Navigation software in the computer uses the position information from the GPS receiver to display the position of the survey vessel with respect to the planned survey line. Information such as distance off line, vessel speed, distance along line, and heading are also displayed on the computer screen. Such information enables the helmsman to steer the vessel along the desired track lines. Acoustic identification of artificial reefs was determined by visual observation of the acoustics images on the real-time display as well as post image processing. The manual interpretation of the sonographs revealed that most of the artificial reefs were located in a limited area in a southwesterly direction from the center of the permitted site. This phase of surveying is quite important especially for artificial habitat sites where large amounts of artificial reefs were deployed and their actual locations were not well documented.

\section{Detailed Site Surveying}

Based on the information collected during the preliminary site surveying, an area of about $6 \mathrm{~km}^{2}$ was selected for the detailed site surveying operation.
North-south directed tracking lines, with line spacing of about $100 \mathrm{~m}$, were arranged and a navigation system was employed to enable the helmsman to steer the vessel along the desired lines. The side-scan sonar operation settings were $500 \mathrm{kHz}$ with slant range at 75 $\mathrm{m}$. These should provide a $50 \%$ overlap of side scan data. However, due to heavy seas and the interference of fishing boats during the surveying, the planned tracking lines were not followed exactly (Fig. 3) which rendered the image coverage of certain specific locations to be less than $100 \%$ complete.

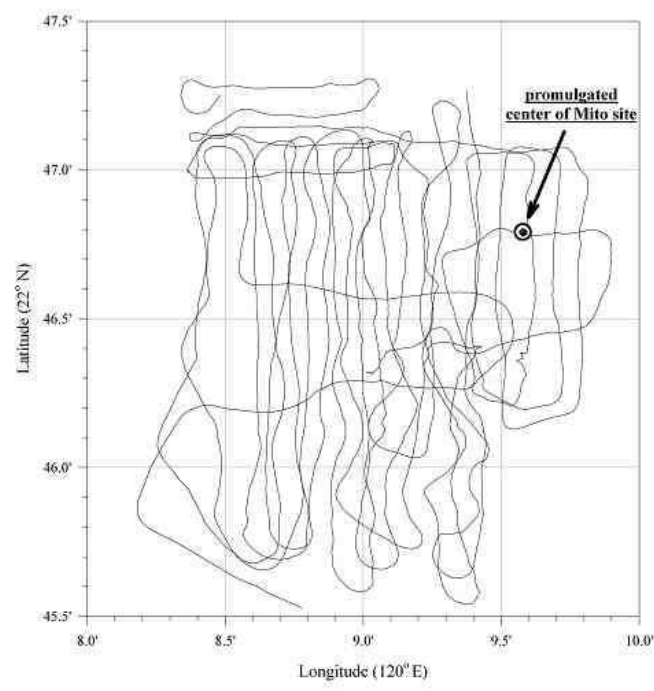

Fig. 3. Tracklines of the detailed side-scan sonar surveying at Mito artificial habitat site.

\section{RESUlts AND Discussions}

The sea floor of the Mito artificial habitat site was found to be rather featureless and sloping gently seaward, with an average gradient of about $0.1^{\circ}$. The bathymetric contours, ranging from 23 to 26 meters, generally run in a N-S direction. Based on the interpretation of side-scan sonar images (Fig. 4) and the texture of two surficial sediment samples, the sediments overlying the sea floor of the Mito site were found to be composed of sandy silt with a mean grain diameter of $80 \mathrm{~mm}$ in the northern portion (coarse grained area) and $39 \mathrm{~mm}$ in the southern portion (fine grained area). A distinctive, curvilinear boundary can be delineated between these two types of sediments.

The manual interpretation of the sonographs revealed that both small and large concrete cubic blocks as well as the steel boats could be detected and recognized individually by virtue of darker image 
shades, highly regularly shaped external configurations with straight edges and physical dimensions, as well as acoustic shadow zones. In addition, further analyses revealed the existence of various types of distribution patterns for both small and large concrete blocks as well as steel boats. These distribution patterns are relevant to the results of various deployment procedures and events and can, therefore, be classified as constituting sparsely, linearly, and closely distributed conditions for cubic blocks (Fig. 5), as well as sparsely and closely distributed conditions for steel boats (Fig. 6). No piling up of either concrete blocks or boats was detected at this site. At one specific spot, side-scan sonar imagery illustrates all three types of distribution patterns of concrete blocks within an area of about $45,000 \mathrm{~m}^{2}$ (i.e., $300 \mathrm{~m} \times 150 \mathrm{~m}$ ) (Fig. 7). Clearly illustrated in the sonographs was the outer appearance of the concrete blocks where no rupture or evidence of breakage could be detected. Therefore, the structure of the concrete reefs is still intact after the passage of at least 10 years. The phenomenon of sediment scouring was evident especially on and in the vicinity of some boats. However, only minor and symmetric scouring depressions existed around these boats. Further, no prominent scouring feature was detected on or around any of the concrete blocks. Since the artificial reefs had been deployed at this site for a period of at least 10 years, the status of these scouring features illustrated that burial, major subsidence or even movement of either concrete blocks or fishing boats in this area is highly doubtful. No evidence of trawl marks on the seafloor was detected at this site which indicated that fishing activity by trawlers had been excluded from this site.

Biological objects, such as schools of fish, in the water column were detected on and around artificial reefs especially in the area close to the steel fishing boats (Fig. 8). In this case, fish act as sonar reflectors both because of the gas carried in their air bladders and by virtue of the makeup of their bodies as constituting discontinuities in the water (FISH; CARR, 1990). The shadows cast by one of the schools can offer quantitative information regarding their population densities and vertical distribution. The existence of groups of fish in this artificial habitat site suggested qualitatively that it is effective in terms of the attraction of fish and the aggregation of organisms.

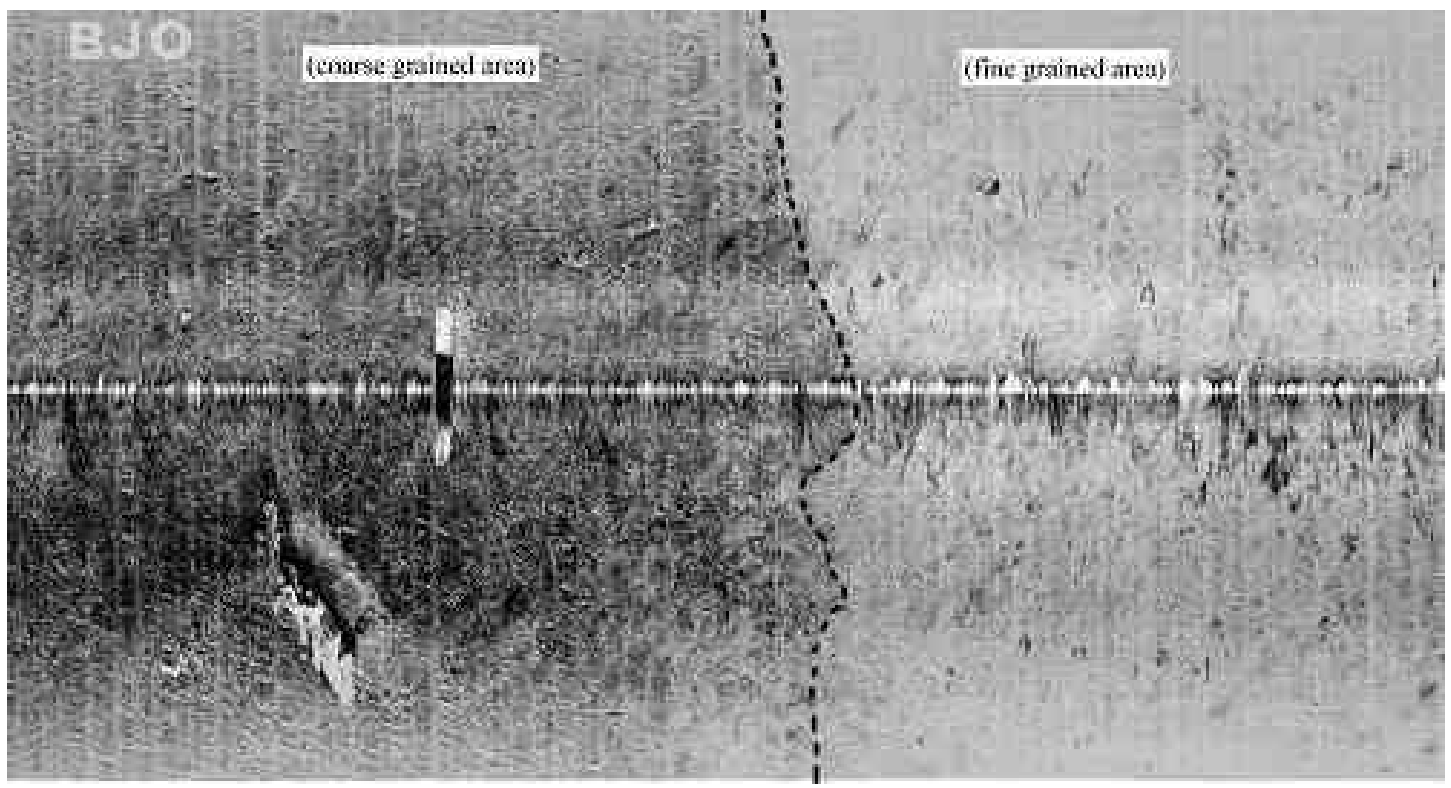

Fig. 4. Side-scan sonar imagery showing two areas of distinct acoustic backscatter and boundary of sediment types. The area shown on the image is about $280 \times 150 \mathrm{~m}$. 


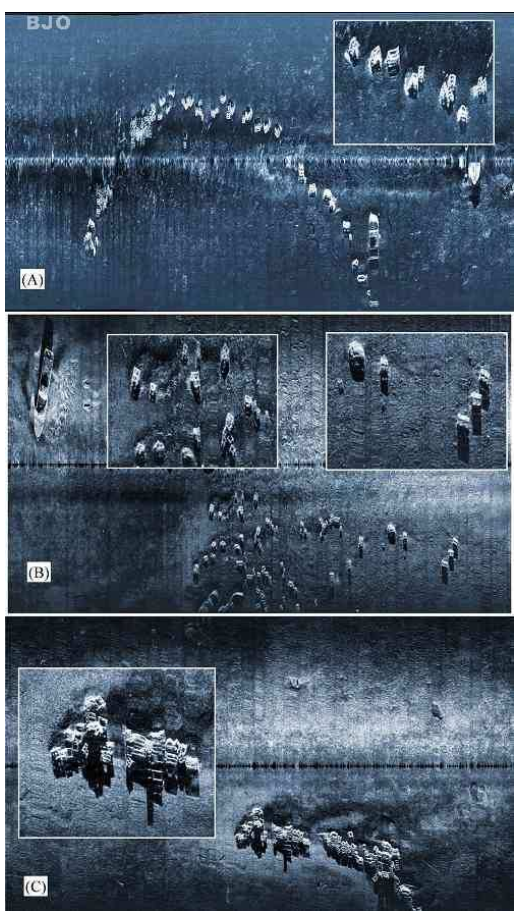

Fig. 5. Side-scan sonar imagery illustrating three types of distribution states of concrete blocks. (A) linearly spaced stat, (B) sparsely spaced state , (C) tightly spaced state. Inserted are the locally enlarged portion of the concrete blocks.

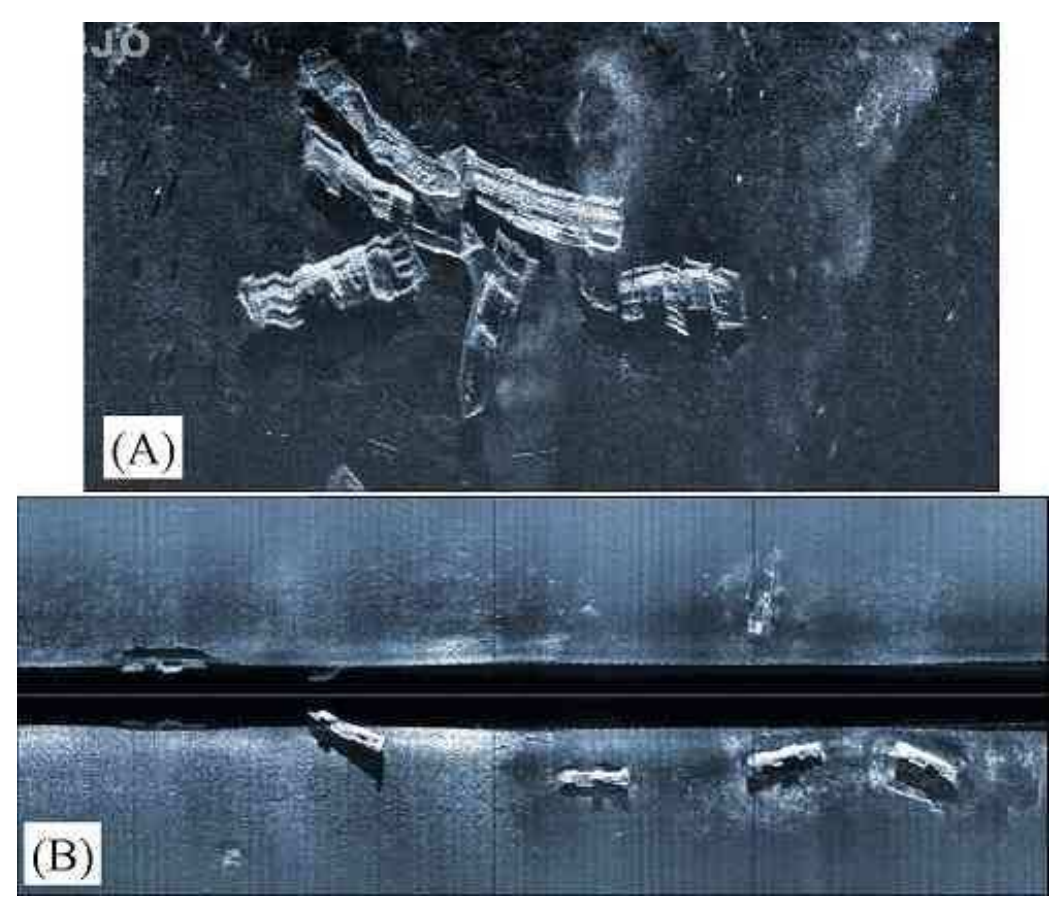

Fig. 6. Side-scan sonar imagery illustrating two types of distribution states of steel fishing boats. (A) tightly spaced state, (B) sparsely spaced state. 


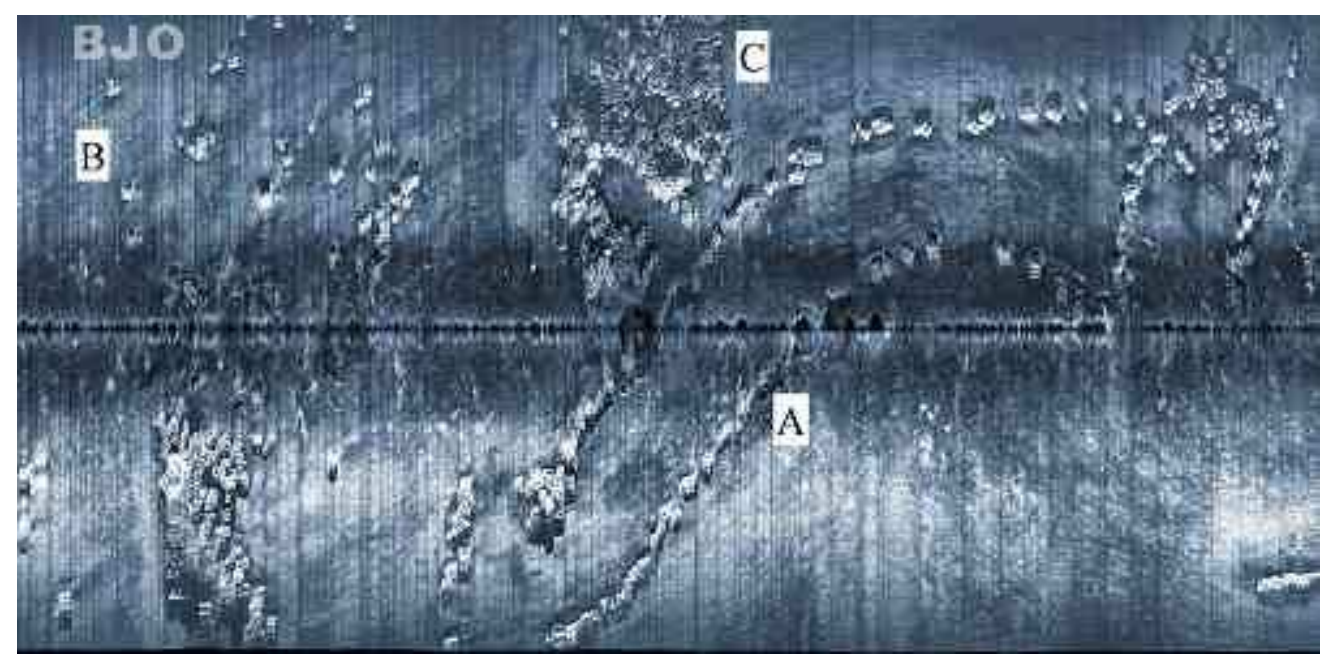

Fig. 7. Side-scan sonar imagery illustrating three types of distribution states of concrete blocks at a specific spot. A- linearly spaced state, B- sparsely spaced state, C- tightly spaced state. The area shown on the image is about $300 \times 150 \mathrm{~m}$.

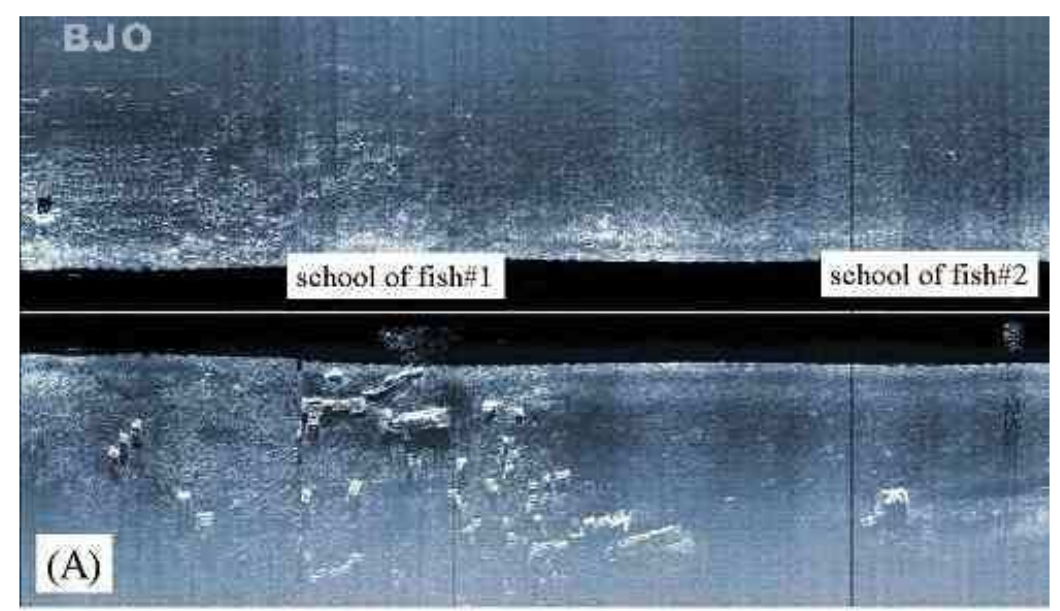

(B)
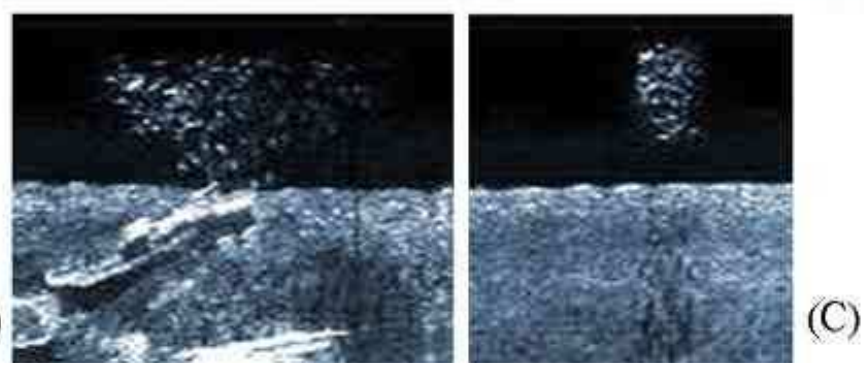

Fig. 8. Side-scan sonar imagery illustrating biological objects on and around artificial habitats. The area shown on the image (A) is about $150 \times 260 \mathrm{~m}$. 
The collected side-scan sonar images were processed to create a mosaic (Fig. 9). A portion of the mosaic with enlarged imagery (Fig. 10) demonstrated the proper perspective and distribution of the artificial reefs. The geographical coordinates of the artificial reefs at this site were then determined and documented (Fig. 11). For those sparsely and linearly spaced concrete blocks and boats, the geographical location of each individual could be identified and therefore the real number of these reefs calculated precisely. However, as regards the closely spaced blocks, the real number of these reefs could not be counted accurately and could only, therefore, be estimated approximately on the basis of the total area covered by the sonograph. A total of 39 steel fishing boats and around 10,000 concrete blocks were in fact detected. The number of reefs detected is closely comparable to the number documented in the deployment records (i.e., 43 boats and 11,170 concrete blocks), the detection rate thus being of $91 \%$ and $90 \%$, respectively. Based on their geographical locations, the concrete cubic artificial reefs could be grouped into 14 reef sets. The normal distance between adjacent reef sets ranged from $50 \mathrm{~m}$ to about $200 \mathrm{~m}$ with an average of approximately 100 $\mathrm{m}$. The number of concrete blocks constituting each reef set ranged from over 100 units to a maximum number of about 1,000 units. According to the artificial reef deployment records of this site, each reef set could be correlated with a specific reef deployment event or several events.

Regarding the geographical coordinates of the reefs, about $30 \%$ of them had been deployed

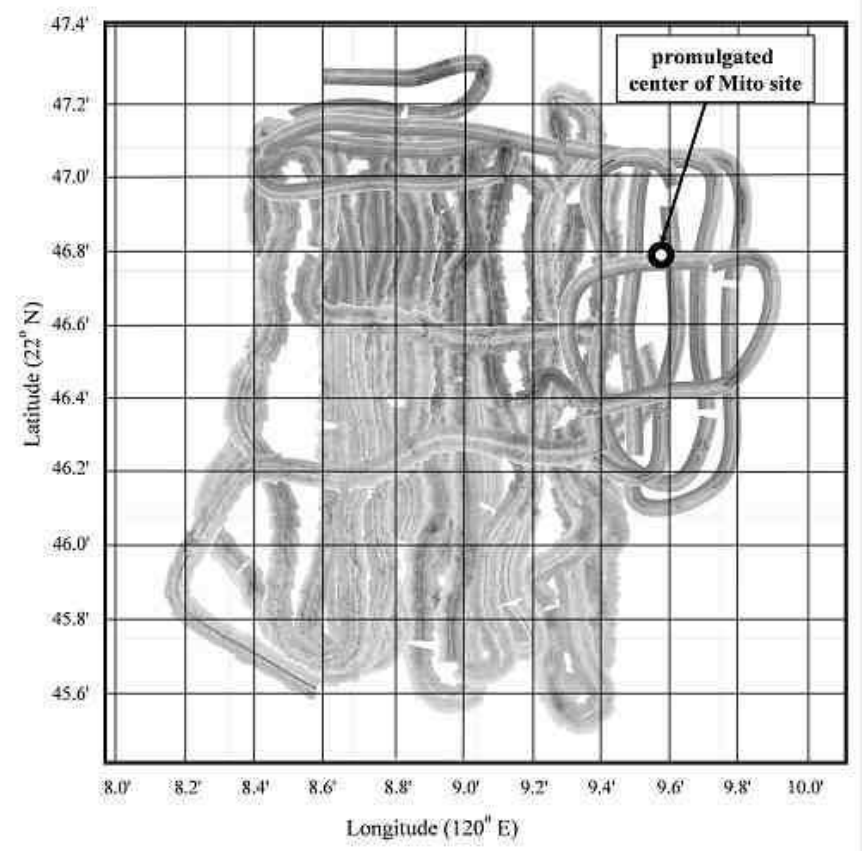

outside the permitted site. The location of the Mito artificial habitat site, based on this investigation, should be modified to be centered at $22^{\circ} 46.495 \mathrm{~N}$, $120^{\circ} 9.238 \mathrm{E}$ with a radius of $1,220 \mathrm{~m}$ (at a probability of $95 \%$ ) and covered an area of $4.7 \mathrm{~km}^{2}$. The difference between the promulgated site center and the modified site center thus turns out to be about $800 \mathrm{~m}$ in distance. The reasons explaining the artificial reefs' deployment outside the permitted site area may include: (i) errors introduced by the positioning instruments utilized (i.e., radar or GPS); (ii) errors introduced by the misinterpretation of deployment locations as between two frequently used map data in the Taiwan area, i.e., WGS-84 datum and GRS-67 datum; (iii) techniques used for barge maneuvering during reef deployment operations.

For the purposes of site identification and management, a database structure was designed to accommodate the physical properties of the artificial habitat site, which included types and positions of reefs, information of reef sets (amount, distribution, normal distance between sets, etc.), bathymetric contours, textures of surficial sediments, and geomorphological characteristics (Fig. 12). The effectiveness of the Mito artificial habitat site was evaluated as positive after the deployment of both concrete block reefs and steel boat reefs, The linkage of this database structure with the geographical information system (GIS) provides basic, practical information for the modeling and management of artificial habitat ecosystems.
Fig. 9. Mosaic of side-scan sonar profiles collected from the study site. 


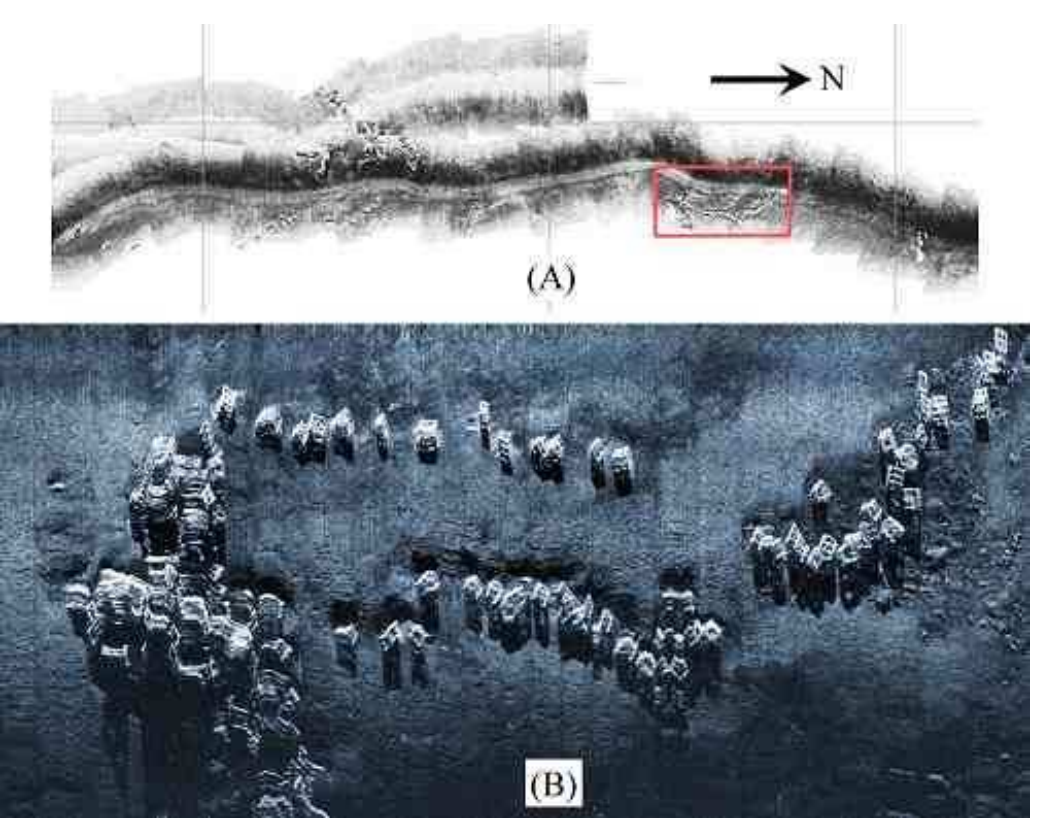

Fig. 10. A portion of the side-scan sonar mosaic with enlarged imagery.

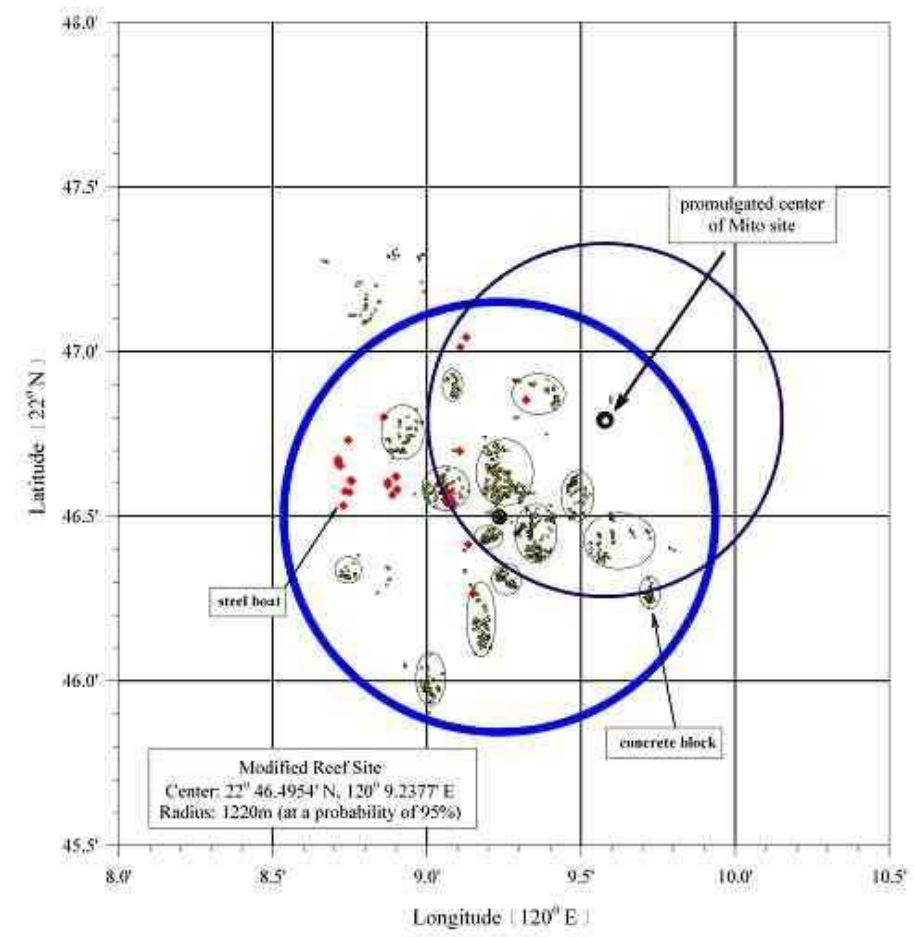

Fig. 11. Positions of concrete blocks and steel boats at Mito artificial habitat site. \&nbsp; The concrete cubic blocks were grouped into 14 reef sets. (Note: The symbles are not to scale with the chart and may cover a much larger portion of the chart than the corresponding materials.) 


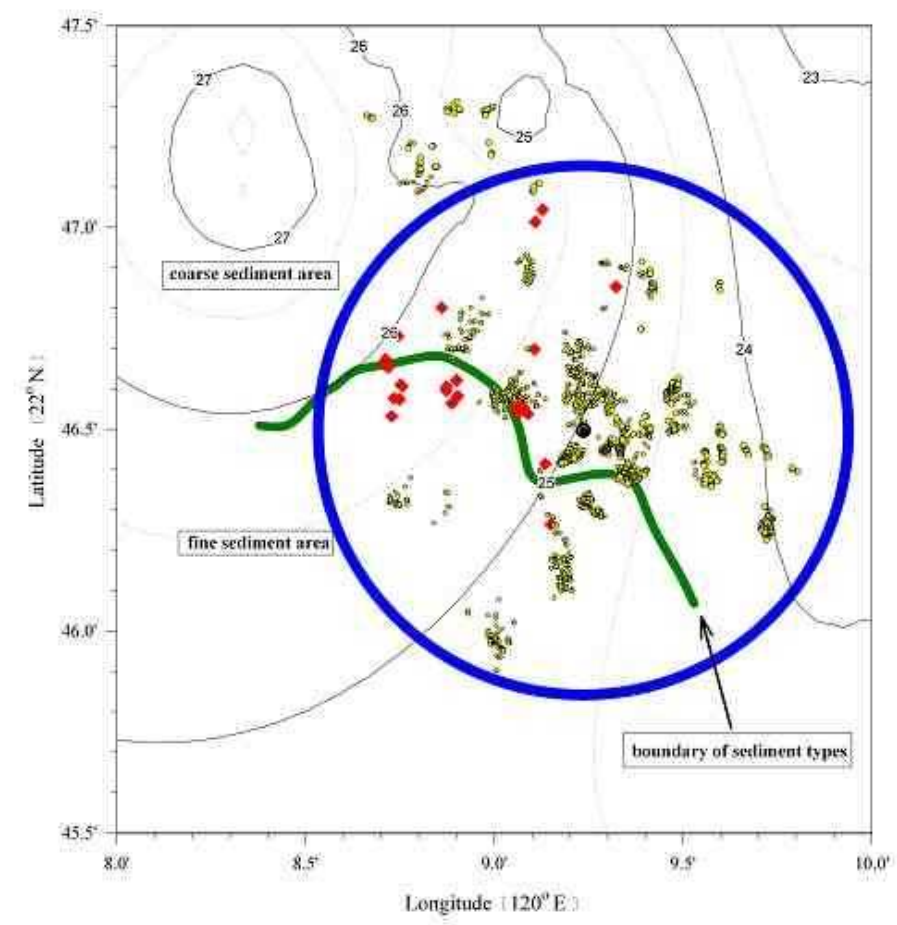

Fig. 12. Example of the database structure estabilished in this investigation. The data in this example includes bathymetric contour, surficial sediments, positions of habitats and \&nbsp; the area of Mito artificial habitat site.

\section{Conclusions}

The results of the research efforts dedicated to the Mito artificial habitat site appear to be both encouraging and promising. The artificial reefs deployed at the Mito artificial habitat site were proved to be physically intact. The burial of concrete blocks in this area is highly debatable. The application of sidescan sonar and related image processing techniques without the assistance of scuba divers or other optical apparatus represents an effective approach to the search for and detection, identification, positioning and monitoring of artificial benthic habitats. The conclusions of this investigation may therefore be summarized as follows:

(1) Two phases of field side-scan sonar surveying operations, i.e., preliminary and detailed site surveying, were suggested for the search for and the detection and location of artificial reefs at an artificial benthic habitat site where the locations of artificial reef deployment are not well documented.

(2) Regarding optimum side-scan sonar parameter settings during a specific surveying operation, 100 $\mathrm{kHz}$ frequency with slant range setting at $100 \mathrm{~m}$ was adequate for a preliminary site surveying operation. However, $500 \mathrm{kHz}$ with slant range setting at $75 \mathrm{~m}$ was suggested for a detailed site surveying operation.

(3) A total of 39 steel fishing boats and around 10,000 concrete blocks, which latter constituted at least $90 \%$ of the artificial reefs deployed, were detected at the Mito artificial habitat site in this investigation. Based on their geographical locations, the concrete cubic artificial reefs could be grouped into 14 reef sets. The distances between adjacent reef sets ranged from $50 \mathrm{~m}$ to about $200 \mathrm{~m}$, with an average of approximately $100 \mathrm{~m}$.

(4) Based on the discussions related to the scouring features around the artificial reefs at this site, it was concluded that burial, major subsidence or even movement, whether of concrete blocks or fishing boats, is highly doubtful.

(5) About $30 \%$ of the reefs were deployed outside the permitted site area. The actual location of the Mito artificial habitat site was centered at $22^{\circ} 46.495 \mathrm{~N}$, $120^{\circ} 9.238 \mathrm{E}$ (WGS84 map datum) with a radius of $1,220 \mathrm{~m}$, which differs from the permitted site center by a distance of about $800 \mathrm{~m}$.

(6) After the deployment of both concrete block reefs and steel boat reefs, the effectiveness of the Mito artificial habitat site was assessed as positive on 
the basis of the data on the physical properties collected in this investigation. Further biological, related investigations, including questions regarding organisms aggregated at the site and organisms encrusted on the artificial reefs, are recommended before a comprehensive evaluation of the site's effectiveness as regards either physical or biological aspects can be undertaken.

\section{ACKNOWLEDGMENTS}

The author is grateful for the financial support provided by the National Science Council of the Republic of China (ROC) (NSC96-2221-E-110101, NSC97-2221-E-110-083), and the assistance of Captain E. R. Wu and his crew of the Ocean Research\#3 during this field study. Thanks are also due to Dr. J. C. Hsu of the National Sun Yet-sen University for offering valuable suggestions on the manuscript.

\section{REFERENCES:}

ANDERSON, J. T.; HOLLIDAY, D. V.; KLOSER, R.; REID, D. G.; SIMARD, Y. Acoustic seabed classification: current practice and future directions. ICES J. mar. Sci., v. 65, p. 1004-1011, 2008.

BELL, M.; HALL, J. W. Effects of Hurricane Hugo on south Carolina's marine artificial reefs. Bull. mar. Sci., v. 55, p. 836- 847, 1994.

BLONDEL, PH. Automatic mine detection by textural analysis of COTS sidescan sonar imagery. Int. J. Remote Sens., v. 21, n. 6, p. 3115-3128, 2000.

BLONDEL, PH.; MURTON, B. J. Handbook of seafloor sonar imagery. Chichester, Eng.: Praxis Publishing, 1997.

CHEN, M. P.; CHERN Y. C. Sedimentary structure and acoustic characteristics of surficial sediments off Southwest Taiwan. National Taiwan University, 1997.

CHOU, L. M. Artificial reefs of Southeast Asia-Do they enhance or degrade the marine environment? Environ. Monitoring Assessment, v. 44, p. 45-52, 1997.

COLLIER, J. S.; BROWN, C. J. Correlation of sidescan backscatter with grain size distribution of surficial seabed sediments, Mar. Geol., v. 214, p. 431-449, 2005.

FISH, J. P.; CARR, H. A. Sound underwater images-A guide to the generation and interpretation of side scan sonar data. Orleans, MA: Lower Cape Publishing, 1990.

FISHERY ADMINISTRATION, TAIWAN. Coastal fishery resources, from the World Wide Web, 2009. $<\mathrm{fttp}: / / \mathrm{www} \cdot f a \cdot g o v \cdot t \mathrm{w}>$

FURUNO Operator's Manual, Color video sounder, Model FCV-582. Nishinomiya, Japan: Furuno Electric Co., 1996.

GROVE, R. S.; ZABLOUDIL, K.; NORALL, T; DEYSHER, L. Effects of El Nino events on natural kelp beds and artificial reefs in southern California. ICES J. mar. Sci., v. 59, p. S330-S337, 2002.

JOHNSON, H. P.; HELFERTY, M. The Interpretation of Side Scan Sonar. Revs Geophys., v. 28, p. 357-380, 1990.
KENNY, A. J.; CATO, I.; DESPREZ, M.; FADER, G.; SCHUTTENHELM, R. T. E.; SIDE, J. An overview of seabed-mapping technologies in the context of marinehabitat classification. ICES J. mar. Sci., v. 60, p. 441418, 2003.

KINSLER, L. E.; FREY, A. R.; COPPENS, A. B.; SANDERS, J. V. Fundamentals of Acoustics. $3^{\text {rd }}$ ed. New York: John Wiley \& Sons, 1982.

LIN, K. P. Fulfillment of conservation for fishery resources. China Acquacult., Monthly; v. 560, p. 29-46. 1999.(In Chinese).

LURTON, X. An introduction to underwater Acoustics: Principles and applications. UK: Praxis Publishing, 2002.

MAZEL C. Side scan sonar training manual. Salem, NH: Klein Associates, Inc., 1985.

MUNOZ-PEREZ, J.J.; MAS, J.M.G.; NARANJO, J.M.; TORRES, E.; FAGES, L. Position and monitoring of anti-trawling reefs in the Cape of Trafalgar (Gulf of Cadiz, SW Spain). Bull. mar. Sci.,v. 67, p. 761- 772, 2000.

OH, S. C.; CHEN, C. C.; CHENG, H. U.; LIU, C. C. Review of artificial reef investigations in Taiwan. Committee of Agriculture Administration Special Publication\#39, R. O. C., 1993. p. 9-23. (In Chinese).

QUINN R.; DEAN, M.,; LAWRENCE, M.; LISCOE, S.; BOLAN, D. Backscatter responses and resolution considerations in archaeological side-scan sonar surveys: a control experiment. J. Archaeol. Sci., v. 32 p. 12521264, 2005.

SEAMAN JR.; SPRAGUE, L. M. Artificial habitat practices in aquatic system. In: SEAMAN JR.; W.; SPRAGUE, L. M. (Ed.). Artificial habitats for marine and freshwater fisheries. San Diego: Academic Press, 1991.

TIAN, W. M. Integrated method for the detection and location of underwater pipelines, Appl. Acoustics, v. 69 , n. 5,p. $387-398,2008$.

TIAN, W. M.; LIN, C. W. (2003) Long-term monitoring and engineering stability analysis of underwater static targets. In: OCEAN ENGINEERING CONFERENCE IN TAIWAN, $25^{\text {th }}$, Tainan, Taiwan, 2003. Proceedings... Tainan, Taiwan, 2003. p. 789-796..

TURPIN, R. K.; BORTONE, S. A. Pre- and post-hurricane assessment of artificial reefs: evidence for potential use as refugia in a fishery management strategy. ICES J. mar. Sci., v. 59, p. S74- S82, 2002.

TYCE, R. C. Deep Ssafloor mapping systems-A review. Mar. Technol. Soc. J., v. 20, n. 4, p. 4-16, 1986.

URICK, R. J. Principles of underwater sound for Engineers. 2nd ed. New York: McGraw-Hill Book Company, 1975.

VIK, S. F. Japanese artificial reef Technology. Maryland: Aquabio Inc., 1982.
(Manuscript received 20 May 2010; revised 03 April 2011; accepted 11 April 2011) 